\title{
Enhanced Recovery after Surgery in a Single High-Volume Surgical Oncology Unit: Details Matter
}

\author{
Timothy L. Fitzgerald, ${ }^{1,2}$ Catalina Mosquera, ${ }^{1,2}$ Nicholas J. Koutlas, ${ }^{1}$ Nasreen A. Vohra, ${ }^{1,2}$ \\ Kimberly V. Edwards, ${ }^{3}$ and Emmanuel E. Zervos ${ }^{1,2}$ \\ ${ }^{1}$ East Carolina University Brody School of Medicine, Division of Surgical Oncology, Greenville, NC 27834, USA \\ ${ }^{2}$ East Carolina University Brody School of Medicine, Department of Surgery, Greenville, NC 27834, USA \\ ${ }^{3}$ Vidant Medical Centre, Division of Dietetics and Nutrition, Greenville, NC 27834, USA \\ Correspondence should be addressed to Timothy L. Fitzgerald; fitzgeraldt@ecu.edu
}

Received 20 March 2016; Accepted 18 July 2016

Academic Editor: Ahmed H. Al-Salem

Copyright (C) 2016 Timothy L. Fitzgerald et al. This is an open access article distributed under the Creative Commons Attribution License, which permits unrestricted use, distribution, and reproduction in any medium, provided the original work is properly cited.

Benefits of ERAS protocol have been well documented; however, it is unclear whether the improvement stems from the protocol or shifts in expectations. Interdisciplinary educational seminars were conducted for all health professionals. However, one test surgeon adopted the protocol. 394 patients undergoing elective abdominal surgery from June 2013 to April 2015 with a median age of 63 years were included. The implementation of ERAS protocol resulted in a decrease in the length of stay (LOS) and mortality, whereas the difference in cost was found to be insignificant. For the test surgeon, ERAS was associated with decreased LOS, cost, and mortality. For the control providers, the LOS, cost, mortality, readmission rates, and complications remained similar both before and after the implementation of ERAS. An ERAS protocol on the single high-volume surgical unit decreased the cost, LOS, and mortality.

\section{Introduction}

The concept of enhanced recovery after surgery (ERAS) involves the integration of evidence-based medicine into clinical practice to improve patient outcomes. The application of new evidence is often delayed and inconsistently adapted into clinical care [1-3]. The genesis of ERAS is associated with the colonic surgeries of the 1990s and is often attributed to Professor Henrik Kehlet of Copenhagen [4]. Kehlet reported length of stays (LOS) of 2-3 days for patients undergoing colonic surgery in an era when LOS was typically more than 9 days. The term ERAS was coined in 2001 by a group of academic surgeons in Europe working on protocols for colon surgery [5], who were heavily influenced by Kehlet's remarkable results.

The basic tenets of ERAS include the adoption of evidence-based practices to decrease surgical stress, maintain physiologic homeostasis, and facilitate recovery of patients $[6,7]$. Although individual components may vary, most of the ERAS programs include avoidance of fasting, optimization of health, preoperative carbohydrate loading, avoidance of bowel preparation, goal-directed resuscitation, multimodal analgesia with avoidance of opiates, avoidance/early removal of tubes (nasogastric tube, Foley catheter, and drains), support of gastrointestinal function, and early convalescence $[4,7,8]$. When these principles are applied to the patients undergoing colonic surgery, factors such as LOS, complications, and readmission rates are noted to have decreased [810]. Improved outcomes with ERAS implementation in colon surgery have been documented in randomized controlled trials and structured nationwide programs [11, 12].

The majority of data on ERAS focus on colon surgeries, and its success has encouraged expansion to other major abdominal operations. In a study, Joliat et al. noted a decrease in LOS and cost after pancreaticoduodenectomy with an ERAS program [13]. In a systematic review and meta-analysis of nine trials (two were randomized controlled), Hughes et al. reported that ERAS protocols were associated with decreased morbidity and LOS after hepatic resection [14]. Similar results have been reported in cases of bladder, esophagus, gastric, 
TABLE 1: ERAS protocol.

\begin{tabular}{|c|c|c|}
\hline \multicolumn{3}{|l|}{ Preoperative factors } \\
\hline High protein diet & Starting at appointment date & Up to $1 \mathrm{gr} / \mathrm{kg}$, protein/day \\
\hline Immunonutrition & Five days prior to surgery & Ensure complete liquid 1 can BID, Juben power BID \\
\hline Clear liquids only & After midnight on day prior to surgery & Gatorade lemon-lime $20 \mathrm{Oz}$, no cream, no red drinks \\
\hline Last intake & Three hours prior to surgery & Gatorade lemon-lime $20 \mathrm{Oz}$ \\
\hline \multicolumn{3}{|l|}{ Intraoperative factors } \\
\hline Pain control & Throughout the case & Epidural (optional), gabapentin $600 \mathrm{mg}$ once \\
\hline Normothermia & Throughout the case & Bair Huger \\
\hline Fluid resuscitation & Throughout the case & Lidco monitor \\
\hline \multicolumn{3}{|l|}{ Postoperative factors } \\
\hline Pain control & Throughout postoperative time & $\begin{array}{l}\text { Avoid narcotic use, gabapentin } 600 \mathrm{mg} \text { PO q } 8 \mathrm{hrs} \times 3 \text {, } \\
\text { Toradol } 15 \mathrm{mg} \text { IV q } 6 \mathrm{hrs} \times 4 \text {, Tylenol 1,000 iv as needed }\end{array}$ \\
\hline Bowel regimen & Until return of bowel function & $\begin{array}{l}\text { Colace } 100 \mathrm{mg} \text { PO q } 12 \mathrm{hrs,} \mathrm{Dulcolax} \mathrm{suppository} 10 \mathrm{mg} \\
\text { PR q } 24 \mathrm{hrs}\end{array}$ \\
\hline Diet & Early enteral nutrition & Immunonutrition $\times 5$ days, diet as tolerated on POD1 \\
\hline Early convalescence & Postop day 0 & $\begin{array}{l}\text { Up to chair } 6-8 \mathrm{hrs} \text {, ambulation in the halls } 5 \text { times a } \\
\text { day }\end{array}$ \\
\hline Drain management & Postop days $0-1$ & NGT removed on postoperative days $0-1$ \\
\hline
\end{tabular}

bariatric, gynecologic, and emergent surgeries that have implemented the ERAS protocols [15-25].

To better understand the application of ERAS protocol in a diverse patient population and the influence of shifting expectations on non-ERAS patients, we reviewed a pilot program involving a single gastrointestinal oncology surgeon on a closed surgical oncology unit. Our hypothesis was that a single protocol encompassing the tenets of ERAS when applied to a myriad of complex abdominal procedures would improve the patient outcomes. In addition, we also hypothesized that education of perioperative staff and changes in the postoperative expectations would improve the outcomes in the unit's control (non-ERAS) population.

\section{Methods}

2.1. Data Source. Patients undergoing only elective abdominal surgeries from June 2013 until April 2015 at Vidant Medical Center, East Carolina University, Greenville, North Carolina, were included in this study. Patients of three attending surgical oncologists were retrospectively identified from the University Health Consortium (UHC) database using the primary procedure codes. Patients who underwent emergent or urgent procedures were excluded. All patients undergoing minor nonabdominal or abdominal procedures were also excluded. The excluded abdominal procedures included soft tissue excision, open liver biopsy, closed liver biopsy, and excision of lymph nodes. The demographics, operative factors, and weighted financial data of the patients were collected. The electronic health record was utilized for data that was unclear in the UHC dataset or was unavailable. The age-adjusted Charlson Comorbidity Index (CCI) was calculated for each patient using comorbidities within the UHC dataset and ICD-9 codes. Then the patients were divided into three subcategories based on their CCI score: low, with CCI scores of 1-2; intermediate, with CCI scores of 3-5; and high, with CCI scores of $>5$. The surgical procedures were divided into six subcategories: pancreatectomy, intestinal resection, hepatic resection, colostomy, gastrectomy, and other major abdominal surgeries. The LOS, in-hospital mortality, readmission within 30 days, and postoperative complications were recorded. The Clavien-Dindo score was utilized to classify postoperative complications. All costs during the index admission period were calculated using the adjusted financial data within the UHC dataset.

2.2. Implementation of Protocol. A protocol was developed that utilized the published guidelines by the ERAS Society for pancreatic, colonic, and rectal/pelvic surgeries [26, 27]. The goal was to develop a single perioperative process that could be applied to a diverse group of patients. Protocol components included preoperative immunonutrition, clear liquids until 2 hours before surgery, carbohydrate loading until 2-3 hours before surgery, epidural catheter offered to all patients undergoing laparotomy, loading dose of gabapentin, intraoperative goal-directed resuscitation with LIDCO monitor (LIDCO Ltd., London, UK), maintenance of normothermia, multimodal pain management with avoidance of narcotics, avoidance of nasogastric tubes, early removal of drains, perioperative bowel regiment, postoperative immunonutrition, and early aggressive convalescence (Table 1).

As controversies existed around the impact of enhanced recovery programs versus shifting expectations, patients from a single health care provider were used for tests of change; however, educational interventions included all the staff members. Educational interventions targeted anesthesiologists and anesthetists, dieticians, postoperative nursing staffs, preoperative nursing staffs, and surgical residents. Multiple educational conferences were delivered to the aforementioned key stakeholder groups involved in the health care 
program for patients at a single and closed surgical oncology unit. In addition, the surgeon, clinical nursing staffs, and a registered dietitian performed patient education during the preoperative visit. Patients were also provided with written instructions. The ERAS protocol was implemented on the patients from a single provider in June 2014 (test surgeon) whereas the patients from other health care providers served as the internal control individuals.

Logistic regression was undertaken to determine differences between patients included in the ERAS protocol (test surgeon after 2014) versus those managed without ERAS (test surgeon before 2014 and control surgeons). ERAS outcomes were also analyzed for the test surgeon, comparing patients before and after protocol implementation. Lastly differences in outcomes were evaluated for the control surgeons before and after implementation of protocol by the test surgeon in 2014 .

2.3. Statistical Analysis. Patient demographics, in addition to their operative and financial variables, were represented as means or medians as necessary. Student's $t$-test and chisquare test were performed for univariate analysis. Variables, having a $p$ value $<0.2$ in univariate analysis, were included in all multivariate models. A $p$ value $<0.05$ was defined as statistically significant. The analysis was conducted by using JMP Pro Version 10.0.0 (SAS Institute Incorporated, Cary, North Carolina, USA, 2012).

\section{Results}

3.1. Demographics. A total of 394 patients met the inclusion criteria and were included in this study. The mean age of the included patients was 62.3 years (Table 2). The patients were evenly distributed between genders, and white was found to be the most common racial category (59.9\%). A majority of the patients were diagnosed with colorectal, pancreatic, hepatic (primary or secondary), gastric, or small bowel cancer. In addition, most of the patients had low (40.4\%) or intermediate $(39.6 \%)$ CCI scores. The most common surgical procedure was other abdominal procedure followed by pancreatectomy, intestinal resection, colectomy, hepatic resection, and gastrectomy surgeries. Two surgeons, the test surgeon and a second surgical oncologist, performed a majority of the procedures. The mean and median values of LOS were 6 and 7.6 days, respectively, and the median hospital cost was $\$ 20,998$. The in-hospital mortality rate was $2.3 \%$.

3.2. ERAS versus Non-ERAS. In order to understand the implications of the ERAS program, we divided the patients into ERAS and non-ERAS groups (Table 3). We found that patients were similar in gender, age, race, diagnosis, comorbidities, and surgical procedures in both groups. There was a decrease of 2 days in mean LOS $(p=0.016)$. The in-hospital mortality was also significantly lower in the ERAS group ( 0 versus $2.9 \%, p=0.033)$. Cost $(\$ 18,716$ versus $\$ 21,294)$ and readmission rates (16 versus $11.5 \%$ ) were higher for nonERAS patients, but these differences did not reach statistical significance $(p=0.60$ and 0.21 , resp.). The complication rates were similar.
TABLE 2: Demographics for all patients on a single surgical unit, 2013-2015.

\begin{tabular}{|c|c|c|}
\hline Factor & Percent & Number \\
\hline \multicolumn{3}{|l|}{ Gender } \\
\hline Male & 48.2 & 190 \\
\hline Female & 51.8 & 204 \\
\hline \multicolumn{3}{|l|}{ Age } \\
\hline Median & 63 & $20-93$ \\
\hline Mean & 62.5 & 12.9 \\
\hline \multicolumn{3}{|l|}{ Race } \\
\hline White & 59.9 & 236 \\
\hline Black & 36.5 & 144 \\
\hline Other & 3.6 & 14 \\
\hline \multicolumn{3}{|l|}{ Diagnosis } \\
\hline Other abdominal & 33.0 & 127 \\
\hline Colorectal cancer & 28.1 & 108 \\
\hline Pancreatic cancer & 15.8 & 61 \\
\hline Liver malignancies & 10.1 & 39 \\
\hline Gastric cancer & 6.5 & 25 \\
\hline Small bowel cancer & 6.5 & 25 \\
\hline \multicolumn{3}{|l|}{ Charlson index } \\
\hline $0-2$ (low) & 40.4 & 159 \\
\hline 3-5 (intermediate) & 39.6 & 156 \\
\hline$>5$ (high) & 20.0 & 79 \\
\hline \multicolumn{3}{|l|}{ Surgery } \\
\hline Other abdominal & 24.1 & 95 \\
\hline Pancreatectomy & 21.1 & 83 \\
\hline Intestinal resection & 18.3 & 72 \\
\hline Hepatic resection & 13.7 & 54 \\
\hline Colectomy & 17.0 & 67 \\
\hline Gastrectomy & 5.8 & 23 \\
\hline \multicolumn{3}{|l|}{ Provider } \\
\hline Test physician & 45.4 & 179 \\
\hline Control physician 1 & 44.9 & 177 \\
\hline Control physician 2 & 9.6 & 38 \\
\hline \multicolumn{3}{|l|}{ ERAS } \\
\hline Yes & 22.1 & 87 \\
\hline No & 77.9 & 307 \\
\hline \multicolumn{3}{|l|}{ LOS } \\
\hline Median & 6 & $1-55$ \\
\hline Mean & 7.6 & 6.9 \\
\hline \multicolumn{3}{|l|}{ Cost } \\
\hline Median & 20,998 & $6,052-174,537$ \\
\hline Mean & 25,040 & 18,700 \\
\hline \multicolumn{3}{|l|}{ Complications } \\
\hline Grade 0-I & 63.2 & 249 \\
\hline Grade II-V & 36.8 & 145 \\
\hline Readmissions & 15.7 & 61 \\
\hline Mortality rate & 2.3 & 9 \\
\hline
\end{tabular}


TABLE 3: ERAS versus non-ERAS (control) patients on a single surgical unit, 2013-2015.

\begin{tabular}{|c|c|c|c|}
\hline Factor & ERAS\% (number) & Non-ERAS\% (number) & $p$ value \\
\hline \multicolumn{4}{|l|}{ Gender } \\
\hline Male & $46.0(40)$ & $48.9(150)$ & \multirow{2}{*}{0.63} \\
\hline Female & $54.0(47)$ & $51.1(157)$ & \\
\hline \multicolumn{4}{|l|}{ Age } \\
\hline Median & $62(20-93)$ & $63(22-88)$ & \multirow{2}{*}{0.36} \\
\hline Mean & $61.4(13.9)$ & $62.8(12.6)$ & \\
\hline \multicolumn{4}{|l|}{ Race } \\
\hline White & $62.1(54)$ & $59.3(182)$ & \multirow{3}{*}{0.89} \\
\hline Black & $34.5(30)$ & $37.1(114)$ & \\
\hline Other & $3.5(3)$ & $3.6(11)$ & \\
\hline \multicolumn{4}{|l|}{ Diagnosis } \\
\hline Gastric cancer & $4.8(4)$ & $7.0(21)$ & \multirow{6}{*}{0.45} \\
\hline Small bowel cancer & $8.4(7)$ & $6.0(18)$ & \\
\hline Colorectal cancer & $24.1(20)$ & $29.1(88)$ & \\
\hline Pancreatic cancer & $21.7(18)$ & $14.2(43)$ & \\
\hline Primary and secondary liver malignancies & $12.1(10)$ & $9.6(29)$ & \\
\hline Other abdominal & $28.9(24)$ & $34.1(103)$ & \\
\hline \multicolumn{4}{|l|}{ Charlson index } \\
\hline $0-2$ & $43.7(38)$ & $39.4(121)$ & \multirow{3}{*}{0.76} \\
\hline $3-5$ & $36.8(32)$ & $40.4(124)$ & \\
\hline$>5$ & $19.5(17)$ & $20.2(62)$ & \\
\hline \multicolumn{4}{|l|}{ Surgery } \\
\hline Pancreatectomy & $27.6(24)$ & $19.2(59)$ & \multirow{6}{*}{0.49} \\
\hline Colectomy & $12.6(11)$ & $18.2(56)$ & \\
\hline Hepatic resection & $12.6(11)$ & $14.0(43)$ & \\
\hline Gastrectomy & $4.6(4)$ & $6.2(19)$ & \\
\hline Intestinal resection & $16.1(14)$ & $18.9(58)$ & \\
\hline Other abdominal & $26.4(23)$ & $23.5(72)$ & \\
\hline \multicolumn{4}{|l|}{ LOS } \\
\hline Median & $5(1-39)$ & $6(1-55)$ & \multirow{2}{*}{0.016} \\
\hline Mean & $6.0(4.9)$ & $8.0(7.3)$ & \\
\hline \multicolumn{4}{|l|}{ Complications } \\
\hline Grade 0-I & $67.8(59)$ & $61.9(190)$ & \multirow{2}{*}{0.31} \\
\hline Grade II-V & $32.2(28)$ & $38.1(117)$ & \\
\hline \multicolumn{4}{|l|}{ Cost } \\
\hline Median & $\$ 18,716(\$ 7,937-\$ 93,804)$ & $\$ 21,294(\$ 6,032-\$ 174,537)$ & \multirow{2}{*}{0.060} \\
\hline Mean & $\$ 21,674(\$ 12,118)$ & $\$ 25,994(\$ 20,092)$ & \\
\hline \multicolumn{4}{|l|}{ Readmissions } \\
\hline Readmission rate & $11.5(10)$ & $16.9(51)$ & 0.21 \\
\hline \multicolumn{4}{|l|}{ Mortality } \\
\hline Mortality rate & $0(0)$ & $2.9(9)$ & 0.033 \\
\hline
\end{tabular}

\section{Tests of Change in Single Provider}

4.1. Enhanced Recovery versus Standard Care. Pre- and postERAS outcomes were studied for the test provider (Table 4). Patients in both the groups were similar in gender, age, race, diagnosis, and comorbidities. Mean LOS was significantly decreased during the post-ERAS implementation phase (9.6 days pre-ERAS versus 6.2 days post-ERAS, $p=0.024)$. Costs were also significantly different $(\$ 21,674$ versus $\$ 30,380 ; p=$
0.029). The in-hospital mortality rate was also lower in the post-ERAS phase ( 0 versus $3.3 \%, p=0.044$ ). The increase in the number of pancreatectomies, major complications, and readmission rates failed to reach statistical significance.

4.2. Impact of Changing Culture on Nonparticipating Surgeons. In order to validate the hypothesis that changes after ERAS protocol implementation on this closed, surgical oncology 
TABLE 4: ERAS versus non-ERAS (control) for test surgeon, 2013-2015.

\begin{tabular}{|c|c|c|c|c|c|}
\hline Factor & ERAS\% (number) & No ERAS\% (number) & $p$ value & OR & $p$ value \\
\hline \multicolumn{6}{|l|}{ Gender } \\
\hline Male & $46.0(40)$ & $46.7(43)$ & \multirow{2}{*}{0.92} & & \\
\hline Female & $54.0(47)$ & $53.3(49)$ & & & \\
\hline \multicolumn{6}{|l|}{ Age } \\
\hline Median & $62(20-93)$ & $63(28-88)$ & \multirow{2}{*}{0.41} & & \\
\hline Mean & $61.4(13.9)$ & $63.1(13.9)$ & & & \\
\hline \multicolumn{6}{|l|}{ Race } \\
\hline White & $62.1(54)$ & $60.9(56)$ & \multirow{3}{*}{0.95} & & \\
\hline Black & $34.5(30)$ & $34.8(32)$ & & & \\
\hline Other & $3.4(3)$ & $4.3(4)$ & & & \\
\hline \multicolumn{6}{|l|}{ Diagnosis } \\
\hline Gastric cancer & $4.8(4)$ & $12.0(11)$ & \multirow{6}{*}{0.35} & & \\
\hline Small bowel cancer & $8.4(7)$ & $5.4(5)$ & & & \\
\hline Colorectal cancer & $24.1(20)$ & $26.1(24)$ & & & \\
\hline Pancreatic cancer & $21.7(18)$ & $13.0(12)$ & & & \\
\hline Liver malignancies & $12.1(10)$ & $15.2(14)$ & & & \\
\hline Other abdominal & $28.9(24)$ & $28.3(26)$ & & & \\
\hline \multicolumn{6}{|l|}{ Charlson index } \\
\hline $0-2$ & $43.7(38)$ & $47.8(44)$ & \multirow{3}{*}{0.46} & & \\
\hline $3-5$ & $36.8(32)$ & $28.3(26)$ & & & \\
\hline$>5$ & $19.5(17)$ & $23.9(22)$ & & & \\
\hline \multicolumn{6}{|l|}{ Surgery } \\
\hline Pancreatectomy & $27.6(24)$ & $14.1(13)$ & \multirow{6}{*}{0.064} & 2.07 & 0.069 \\
\hline Colectomy & $12.6(11)$ & $12.0(11)$ & & Referent & Referent \\
\hline Hepatic resection & $12.6(11)$ & $20.7(19)$ & & 1.30 & 0.58 \\
\hline Gastrectomy & $4.6(4)$ & $12.0(11)$ & & 1.07 & 0.91 \\
\hline Intestinal resection & $16.1(14)$ & $21.7(20)$ & & 1.23 & 0.64 \\
\hline Other abdominal & $26.4(23)$ & $19.5(18)$ & & 1.63 & 0.23 \\
\hline \multicolumn{6}{|l|}{ LOS } \\
\hline Median & $5(1-39)$ & $6(1-55)$ & \multirow{2}{*}{0.024} & & \\
\hline Mean & $6.2(4.9)$ & $9.6(9.3)$ & & & \\
\hline \multicolumn{6}{|l|}{ Complications } \\
\hline Grade 0-I & $67.8(59)$ & $54.4(50)$ & \multirow{2}{*}{0.064} & & \\
\hline Grade II-V & $32.2(28)$ & $42.6(42)$ & & & \\
\hline \multicolumn{6}{|l|}{ Cost } \\
\hline Median & $18,716(7,937-93,804)$ & $24,395(6,052-174,536)$ & \multirow{2}{*}{0.029} & & \\
\hline Mean & $21,674(12,118)$ & $30,380(25,723)$ & & & \\
\hline Readmission & $11.5(10)$ & $21.4(19)$ & 0.076 & & \\
\hline Mortality & $0(0)$ & $3.3(3)$ & 0.044 & & \\
\hline
\end{tabular}

unit were different from the changes in unit culture and expectations, we examined the nontest physicians' patients before and after the educational programs and ERAS implementation. We found that the patients were similar in gender, age, race, diagnosis, comorbidities, surgical procedures, postoperative LOS, complications, median costs, readmission rate, and mortality. Table 5 shows that the variables before and after the implementation of ERAS in nonparticipating physicians are remarkably similar. This implies that the changes in the patient outcomes are not dependent upon the cultural shifts in patterns of care of the surgical unit.

\section{Conclusion}

ERAS is a multimodal, evidence-based perioperative pathway that has been demonstrated to decrease the cost, LOS, morbidity, and mortality after major surgical interventions. Surgical literature is replete with data describing the outcomes of ERAS implementation in defined patient populations such as colorectal, hepatopancreatobiliary, esophageal, gynecologic, gastric, acute-care, or urologic surgeries $[4,14,15,19,25$, $28,29]$. However, there is a lack of data on the applicability of ERAS to real-world diverse surgical practices. It is also 
TABLE 5: Control providers before and after ERAS implementation, 2013-2015.

\begin{tabular}{|c|c|c|c|}
\hline Factor & Pre-ERAS & Post-ERAS & $p$ value \\
\hline \multicolumn{4}{|l|}{ Gender } \\
\hline Male & $51.3(61)$ & $47.9(46)$ & \multirow{2}{*}{0.63} \\
\hline Female & $48.7(58)$ & $52.1(50)$ & \\
\hline \multicolumn{4}{|l|}{ Age } \\
\hline Median & $63(28-88)$ & $65(22-86)$ & \multirow{2}{*}{0.78} \\
\hline Mean & $62.9(12.1)$ & $62.4(12.2)$ & \\
\hline \multicolumn{4}{|l|}{ Race } \\
\hline White & $59.7(71)$ & $57.3(55)$ & \multirow{3}{*}{0.93} \\
\hline Black & $37.0(44)$ & $39.6(38)$ & \\
\hline Other & $3.4(4)$ & $3.1(3)$ & \\
\hline \multicolumn{4}{|l|}{ Diagnosis } \\
\hline Gastric cancer & $2.5(3)$ & $7.7(7)$ & \multirow{6}{*}{0.43} \\
\hline Small bowel cancer & $7.6(9)$ & $4.4(4)$ & \\
\hline Colorectal cancer & $33.6(40)$ & $26.4(24)$ & \\
\hline Pancreatic cancer & $14.3(17)$ & $15.4(14)$ & \\
\hline Liver malignancies & $6.7(8)$ & $7.7(7)$ & \\
\hline Other abdominal & $35.3(42)$ & $38.5(35)$ & \\
\hline \multicolumn{4}{|l|}{ Charlson index } \\
\hline $0-2$ & $34.5(41)$ & $37.5(36)$ & \multirow{3}{*}{0.36} \\
\hline $3-5$ & $49.6(59)$ & $40.6(39)$ & \\
\hline$>5$ & $16.0(19)$ & $21.9(21)$ & \\
\hline \multicolumn{4}{|l|}{ Surgery } \\
\hline Pancreatectomy & $19.3(23)$ & $24.0(23)$ & \multirow{6}{*}{0.51} \\
\hline Colectomy & $21.9(26)$ & $19.8(19)$ & \\
\hline Hepatic resection & $11.8(14)$ & $10.4(10)$ & \\
\hline Gastrectomy & $1.7(2)$ & $6.3(6)$ & \\
\hline Intestinal resection & $19.3(23)$ & $15.6(15)$ & \\
\hline Other abdominal & $26.1(31)$ & $24.0(23)$ & \\
\hline \multicolumn{4}{|l|}{ LOS } \\
\hline Median & $6(1-45)$ & $5(1-44)$ & \multirow{2}{*}{0.51} \\
\hline Mean & $7.6(5.9)$ & $7.1(6.3)$ & \\
\hline \multicolumn{4}{|l|}{ Complications } \\
\hline Grade 0-I & $61.3(73)$ & $69.8(67)$ & \multirow{2}{*}{0.20} \\
\hline Grade II-V & $38.7(46)$ & $30.2(29)$ & \\
\hline \multicolumn{4}{|l|}{ Cost } \\
\hline Median & $21,109(6,412-111,409)$ & $20,157(6,951-135,993)$ & \multirow{2}{*}{0.40} \\
\hline Mean & $23,235(13,960)$ & $25,210(19,893)$ & \\
\hline Readmission & $15.1(18)$ & $15.1(14)$ & 0.99 \\
\hline Mortality & $2.5(3)$ & $3.1(3)$ & 0.79 \\
\hline
\end{tabular}

unclear whether the differences in outcomes are attributable to the changes in practice or changes in expectations.

In this study, we found that the principles of ERAS could be applied to various abdominal procedures by utilizing a single perioperative pathway. The utilization of this general ERAS pathway for abdominal procedures, including pancreatectomy, hepatectomy, colectomy, gastrectomy, and small bowel resection, resulted in significant decrease in LOS, cost, and mortality rates. Despite extensive training to nursing staffs of the single and closed surgical oncology unit, there were no changes in outcomes in the unit of non-ERAS (control) patients.

To have maximal impact of ERAS protocol, it must be translatable into settings in which most surgeons practice. Majority of general surgeons do not focus on a specific surgery but rather treat patients with a variety of surgical conditions. In this setting, multiple or individual ERAS pathways for each procedure type may not be practical. Our data also suggested that a more general perioperative pathway would suffice to encompass the principles of 
TABLE 6: Differences in LOS and cost by procedure type in ERAS versus non-ERAS groups, 2013-2015.

\begin{tabular}{|c|c|c|c|c|c|c|c|c|}
\hline \multirow{2}{*}{ Surgery type } & \multicolumn{4}{|c|}{ Mean postop LOS } & \multicolumn{4}{|c|}{ Mean total cost } \\
\hline & ERAS & Non-ERAS & $T$ score & $p$ value & ERAS & Non-ERAS & $T$ score & $p$ value \\
\hline Pancreatectomy & 9.0 & 9.9 & -0.53 & 0.60 & $\$ 30,524$ & $\$ 32,787$ & -0.58 & 0.57 \\
\hline Other abdominal & 5.0 & 6.4 & -1.3 & 0.21 & $\$ 17,713$ & $\$ 21,268$ & -1.3 & 0.19 \\
\hline Colectomy & 5.3 & 7.6 & -1.9 & 0.059 & $\$ 20,733$ & $\$ 24,219$ & -0.91 & 0.37 \\
\hline Intestinal resection & 4.8 & 7.5 & -3.5 & 0.001 & $\$ 18,391$ & $\$ 20,892$ & -0.90 & 0.37 \\
\hline Hepatic resection & 3.8 & 7.4 & -2.9 & 0.0057 & $\$ 16,770$ & $\$ 27,213$ & -3.2 & 0.0030 \\
\hline Gastrectomy & 5.8 & 13.1 & -2.1 & 0.045 & $\$ 18,915$ & $\$ 40,853$ & -2.2 & 0.043 \\
\hline
\end{tabular}

ERAS. The benefits analyzed by utilizing a single set of preoperative instructions, generalized recommendations for perioperative nutrition, and a single postoperative order set were similar to those reported from more focused programs $[8,14,15,19,27,28,30]$. The improvements in outcome measures were most marked for procedures that did not have existing postoperative order sets such as other abdominal, hepatectomy, and gastrectomy compared to pancreatectomy and colectomy procedures that had preexisting postoperative pathways (Table 6).

ERAS perioperative pathways have been demonstrated to decrease the cost of care. When ERAS and non-ERAS patients were compared in this series, we found a marked decrease in the costs of approximately $\$ 2,500$ per patient. Decrease in costs was more in the case of the test surgeon's patients, which was $>\$ 5,000$ per patient. Although these differences did not reach statistical significance, they are in line with those results reported by other investigators. Joliat et al. noted a decrease of 8000 Euros in costs for patients undergoing pancreatectomy procedure after ERAS implementation [13]. Green reported a $\$ 4,800$ decrease in costs for patients undergoing colon surgery [31]. Similar results have been also reported in both North American and European series for gynecologic, bariatric, general, and vascular surgeries [32]. Decreasing costs are likely to result from the shorter LOS and fewer complications.

Evidence on decreased LOS and cost due to the implementation of ERAS protocol after major surgical interventions is compelling. In this study, we noted a marked decrease in LOS approximately by three days. Recent meta-analyses have demonstrated a similar decrease in LOS by 2-3 days after colectomy, 2.5 days after hepatic resection, 1.5 days after gynecologic surgery, and 2-6 days after pancreatectomy surgeries [14, 17, 29].

When implementing an ERAS protocol or any other quality program, it is imperative to examine the pre- and postERAS implementation data to ensure that any unintended consequences are appropriately detected, and the hypothesized improvements actually occurred in patient outcomes. In this study, we also found a decreased risk of mortality rate in the ERAS cohort (0 versus 3\%, $p=0.033$ ). Similarly, we found no increase in the readmission rate, which suggested a trend of potential decrease. These findings were in contrast to most of the reports in which ERAS neither increased nor decreased the readmission or mortality rates [17, 18, 33, 34].
The benefits of ERAS cannot be solely attributed to the changes in the provider's education and recovery expectations. In this study, we found that the improvements in cost, LOS, mortality, and readmission rate were confined to the patients enrolled only in the ERAS protocol. This occurred even though all patients emanated from a single specialty clinic and managed in a single closed surgical unit with the same residents, nursing staffs, attending physicians, and allied health staffs, all of whom were educated regarding the ERAS protocol. This suggests the details matter and that is not ethereal shifts in expectations the drive improvement. This is consistent with several prospective randomized controlled trials examining the impact of ERAS protocol implementation on patient outcomes [14, 35-37]. In addition, several investigators have also reported on the improved outcomes having higher compliance with ERAS components $[5,37,38]$.

In conclusion, ERAS perioperative protocols improve the patient outcomes. Our data collected in context with the current literature demonstrate that the ERAS protocols can be implemented on a wide range of patients undergoing complex abdominal surgeries. Such protocols need not be procedure specific but should incorporate the general principles of ERAS in a single perioperative program. The benefits from such programs include decreased LOS, cost, and mortality rates. It is our hope that these data would demystify the ERAS implementation for the general surgeons and promote its adoption in mixed surgical practices.

\section{Disclosure}

This paper is to be presented at the 11th Annual Academic Surgical Congress.

\section{Competing Interests}

The authors declare that they have no competing interests.

\section{Authors' Contributions}

Catalina Mosquera (acquisition, analysis, interpretation of data, and critical revision), Nicholas J. Koutlas (acquisition, analysis, and conception of work), Nasreen A. Vohra (interpretation of data and critical revision), Kimberly V. Edwards (conception of work and critical analysis), Emmanuel E. Zervos (interpretation of data and critical revision), and Timothy 
L. Fitzgerald (conception of work, analysis, interpretation of data, and critical revision) have contributed to this paper.

\section{References}

[1] S. D. Kachare, J. Brinkley, N. A. Vohra, E. E. Zervos, J. H. Wong, and T. L. Fitzgerald, "Radiotherapy associated with improved survival for high-grade sarcoma of the extremity," Journal of Surgical Oncology, vol. 112, no. 4, pp. 338-343, 2015.

[2] T. L. Fitzgerald, T. Biswas, K. O’Brien, E. E. Zervos, and J. H. Wong, "Neoadjuvant radiotherapy for rectal cancer: adherence to evidence-based guidelines in clinical practice," World Journal of Surgery, vol. 37, no. 3, pp. 639-645, 2013.

[3] T. L. Fitzgerald, E. Zervos, and J. H. Wong, "Patterns of pelvic radiotherapy in patients with stage II/III rectal cancer," Journal of Cancer Epidemiology, vol. 2013, Article ID 408460, 6 pages, 2013.

[4] M. J. Scott, G. Baldini, K. C. H. Fearon et al., "Enhanced Recovery after Surgery (ERAS) for gastrointestinal surgery, part 1: pathophysiological considerations," Acta Anaesthesiologica Scandinavica, vol. 59, no. 10, pp. 1212-1231, 2015.

[5] O. Ljungqvist, "ERAS—enhanced recovery after surgery: moving evidence-based perioperative care to practice," Journal of Parenteral and Enteral Nutrition, vol. 38, no. 5, pp. 559-566, 2014.

[6] U. O. Gustafsson, M. J. Scott, W. Schwenk et al., "Guidelines for perioperative care in elective colonic surgery: enhanced Recovery After Surgery (ERAS $\left.{ }^{\circledR}\right)$ Society recommendations," Clinical Nutrition, vol. 31, no. 6, pp. 783-800, 2012.

[7] J. Segelman and J. Nygren, "Evidence or eminence in abdominal surgery: recent improvements in perioperative care," World Journal of Gastroenterology, vol. 20, no. 44, pp. 16615-16619, 2014.

[8] A. Feldheiser, O. Aziz, G. Baldini et al., "Enhanced Recovery After Surgery (ERAS) for gastrointestinal surgery-part 2: consensus statement for anaesthesia practice," Acta Anaesthesiologica Scandinavica, vol. 60, no. 3, pp. 289-334, 2016.

[9] K. K. Varadhan, K. R. Neal, C. H. Dejong, K. C. Fearon, O. Ljungqvist, and D. N. Lobo, "The enhanced recovery after surgery (ERAS) pathway for patients undergoing major elective open colorectal surgery: a meta-analysis of randomized controlled trials," Clinical Nutrition, vol. 29, pp. 434-440, 2010.

[10] M. Adamina, H. Kehlet, G. A. Tomlinson, A. J. Senagore, and C. P. Delaney, "Enhanced recovery pathways optimize health outcomes and resource utilization: a meta-analysis of randomized controlled trials in colorectal surgery," Surgery, vol. 149, no. 6, pp. 830-840, 2011.

[11] W. R. Spanjersberg, J. Reurings, F. Keus, and C. J. van Laarhoven, "Fast track surgery versus conventional recovery strategies for colorectal surgery," Cochrane Database of Systematic Reviews, vol. 2, Article ID CD007635, 2011.

[12] F. Gillissen, C. Hoff, J. M. C. Maessen et al., "Structured synchronous implementation of an enhanced recovery program in elective colonic surgery in 33 hospitals in the Netherlands," World Journal of Surgery, vol. 37, no. 5, pp. 1082-1093, 2013.

[13] G.-R. Joliat, I. Labgaa, D. Petermann et al., "Cost-benefit analysis of an enhanced recovery protocol for pancreaticoduodenectomy," British Journal of Surgery, 2015.

[14] M. J. Hughes, S. McNally, and S. J. Wigmore, "Enhanced recovery following liver surgery: a systematic review and metaanalysis," $H P B$, vol. 16, no. 8, pp. 699-706, 2014.
[15] N. Sugisawa, M. Tokunaga, R. Makuuchi et al., "A phase II study of an enhanced recovery after surgery protocol in gastric cancer surgery," Gastric Cancer, vol. 19, no. 3, pp. 961-967, 2016.

[16] Y. Cerantola, M. Valerio, B. Persson et al., "Guidelines for perioperative care after radical cystectomy for bladder cancer: enhanced recovery after surgery (ERAS ${ }^{\circledR}$ ) society recommendations," Clinical Nutrition, vol. 32, no. 6, pp. 879-887, 2013.

[17] M. M. E. Coolsen, R. M. Van Dam, A. A. Van Der Wilt, K. Slim, K. Lassen, and C. H. C. Dejong, "Systematic review and metaanalysis of enhanced recovery after pancreatic surgery with particular emphasis on pancreaticoduodenectomies," World Journal of Surgery, vol. 37, no. 8, pp. 1909-1918, 2013.

[18] M. M. E. Coolsen, E. M. Wong-Lun-Hing, R. M. Van Dam et al., "A systematic review of outcomes in patients undergoing liver surgery in an enhanced recovery after surgery pathways," $H P B$, vol. 15, no. 4, pp. 245-251, 2013.

[19] R. L. G. M. Blom, M. Van Heijl, W. A. Bemelman et al., "Initial experiences of an enhanced recovery protocol in esophageal surgery," World Journal of Surgery, vol. 37, no. 10, pp. 2372-2378, 2013.

[20] S. R. Markar, A. Karthikesalingam, and D. E. Low, "Enhanced recovery pathways lead to an improvement in postoperative outcomes following esophagectomy: Systematic review and pooled analysis," Diseases of the Esophagus, vol. 28, no. 5, pp. 468-475, 2015.

[21] Z.-X. Chen, A.-H. J. Liu, and Y. Cen, "Fast-track program vs traditional care in surgery for gastric cancer," World Journal of Gastroenterology, vol. 20, no. 2, pp. 578-583, 2014.

[22] S. Awad, S. Carter, S. Purkayastha et al., "Enhanced Recovery after Bariatric Surgery (ERABS): clinical outcomes from a tertiary referral bariatric centre," Obesity Surgery, vol. 24, no. 5, pp. 753-758, 2014.

[23] L. Wijk, K. Franzen, O. Ljungqvist, and K. Nilsson, "Implementing a structured Enhanced Recovery after Surgery (ERAS) protocol reduces length of stay after abdominal hysterectomy," Acta Obstetricia et Gynecologica Scandinavica, vol. 93, no. 8, pp. 749-756, 2014.

[24] M. Le Guen, J. Fessler, and M. Fischler, "Early oral feeding after emergency abdominal operations: another paradigm to be broken?" Current Opinion in Clinical Nutrition and Metabolic Care, vol. 17, no. 5, pp. 477-482, 2014.

[25] D. Roulin, C. Blanc, M. Muradbegovic, D. Hahnloser, N. Demartines, and M. Hübner, "Enhanced recovery pathway for urgent colectomy," World Journal of Surgery, vol. 38, no. 8, pp. 2153-2159, 2014.

[26] U. O. Gustafsson, M. J. Scott, W. Schwenk et al., "Guidelines for perioperative care in elective colonic surgery: enhanced recovery after surgery (ERAS $\left.{ }^{\circledR}\right)$ society recommendations," World Journal of Surgery, vol. 37, no. 2, pp. 259-284, 2013.

[27] J. Nygren, J. Thacker, F. Carli et al., "Guidelines for perioperative care in elective rectal/pelvic surgery: enhanced recovery after surgery $\left(\right.$ ERAS $\left.^{\circledR}\right)$ society recommendations," World Journal of Surgery, vol. 37, no. 2, pp. 285-305, 2013.

[28] K. C. H. Fearon, O. Ljungqvist, M. Von Meyenfeldt et al., "Enhanced recovery after surgery: a consensus review of clinical care for patients undergoing colonic resection," Clinical Nutrition, vol. 24, no. 3, pp. 466-477, 2005.

[29] J. J. A. de Groot, S. M. C. Ament, J. M. C. Maessen, C. H. C. Dejong, J. M. P. Kleijnen, and B. F. M. Slangen, "Enhanced recovery pathways in abdominal gynecologic surgery: a systematic review and meta-analysis," Acta Obstetricia et Gynecologica Scandinavica, vol. 95, no. 4, pp. 382-395, 2016. 
[30] L. Lee, C. Li, T. Landry et al., "A systematic review of economic evaluations of enhanced recovery pathways for colorectal surgery," Annals of Surgery, vol. 259, no. 4, pp. 670-676, 2014.

[31] F. L. Green, On the Night of the Fire, M. Joseph, London, UK, 1939.

[32] M. D. J. Stowers, D. P. Lemanu, and A. G. Hill, "Health economics in enhanced recovery after surgery programs," Canadian Journal of Anesthesia, vol. 62, no. 2, pp. 219-230, 2015.

[33] J. M. Findlay, E. Tustian, J. Millo et al., "The effect of formalizing enhanced recovery after esophagectomy with a protocol," Diseases of the Esophagus, vol. 28, no. 6, pp. 567-573, 2015.

[34] S. Bona, M. Molteni, R. Rosati et al., "Introducing an enhanced recovery after surgery program in colorectal surgery: a single center experience," World Journal of Gastroenterology, vol. 20, no. 46, pp. 17578-17587, 2014.

[35] A. Karl, A. Buchner, A. Becker et al., "A new concept for early recovery after surgery for patients undergoing radical cystectomy for bladder cancer: results of a prospective randomized study," Journal of Urology, vol. 191, no. 2, pp. 335-340, 2014.

[36] L. Ren, D. Zhu, Y. Wei et al., "Enhanced Recovery after Surgery (ERAS) program attenuates stress and accelerates recovery in patients after radical resection for colorectal cancer: a prospective randomized controlled trial," World Journal of Surgery, vol. 36, no. 2, pp. 407-414, 2012.

[37] D. P. Lemanu, P. P. Singh, K. Berridge et al., "Randomized clinical trial of enhanced recovery versus standard care after laparoscopic sleeve gastrectomy," The British Journal of Surgery, vol. 100, no. 4, pp. 482-489, 2013.

[38] U. O. Gustafsson, J. Hausel, A. Thorell, O. Ljungqvist, M. Soop, and J. Nygren, "Adherence to the enhanced recovery after surgery protocol and outcomes after colorectal cancer surgery," Archives of Surgery, vol. 146, no. 5, pp. 571-577, 2011. 


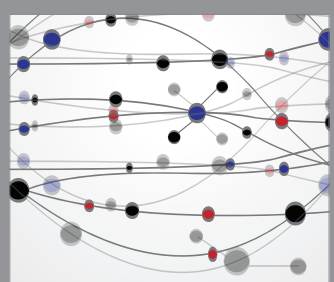

The Scientific World Journal
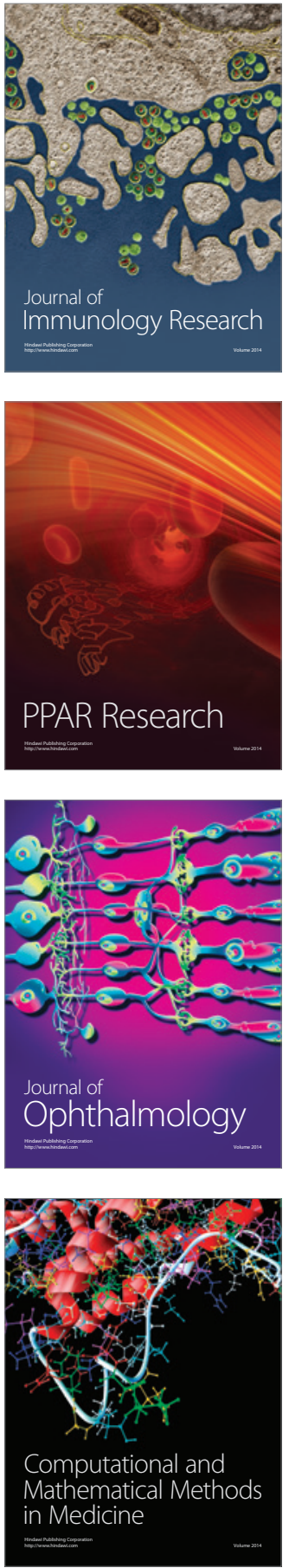

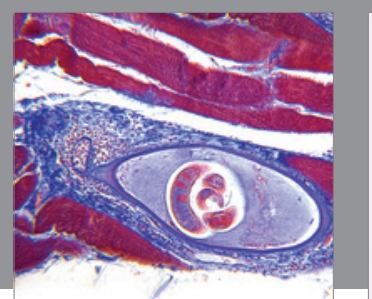

Gastroenterology Research and Practice

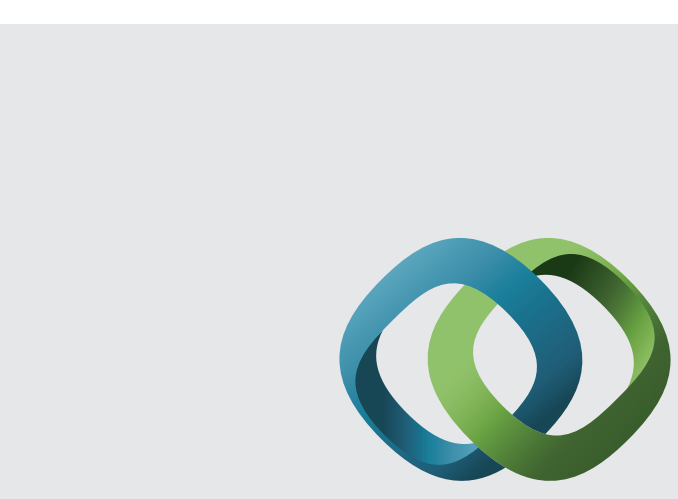

\section{Hindawi}

Submit your manuscripts at

http://www.hindawi.com
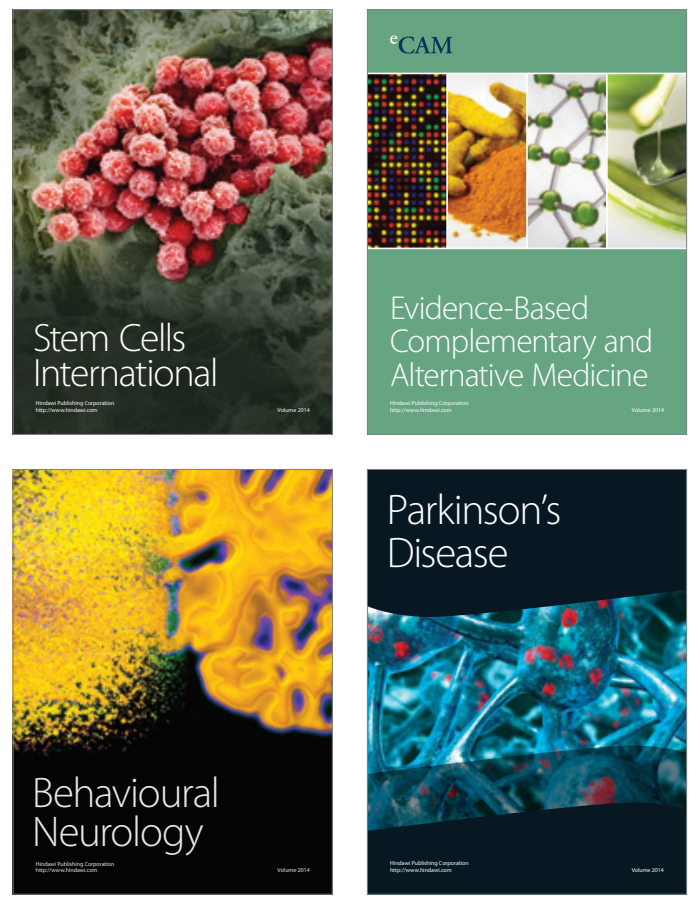
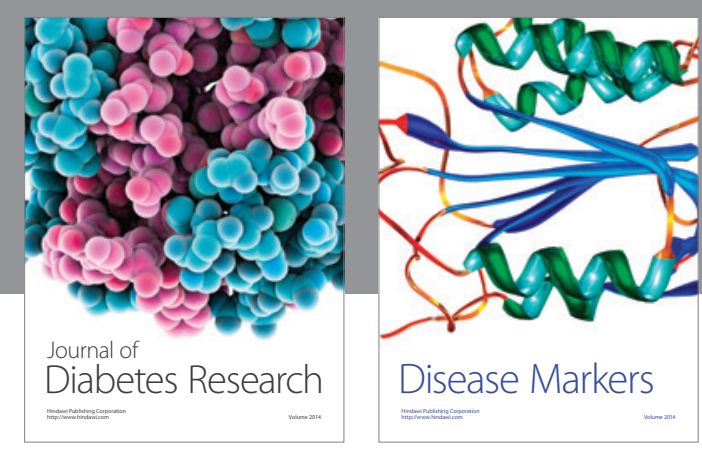

Disease Markers
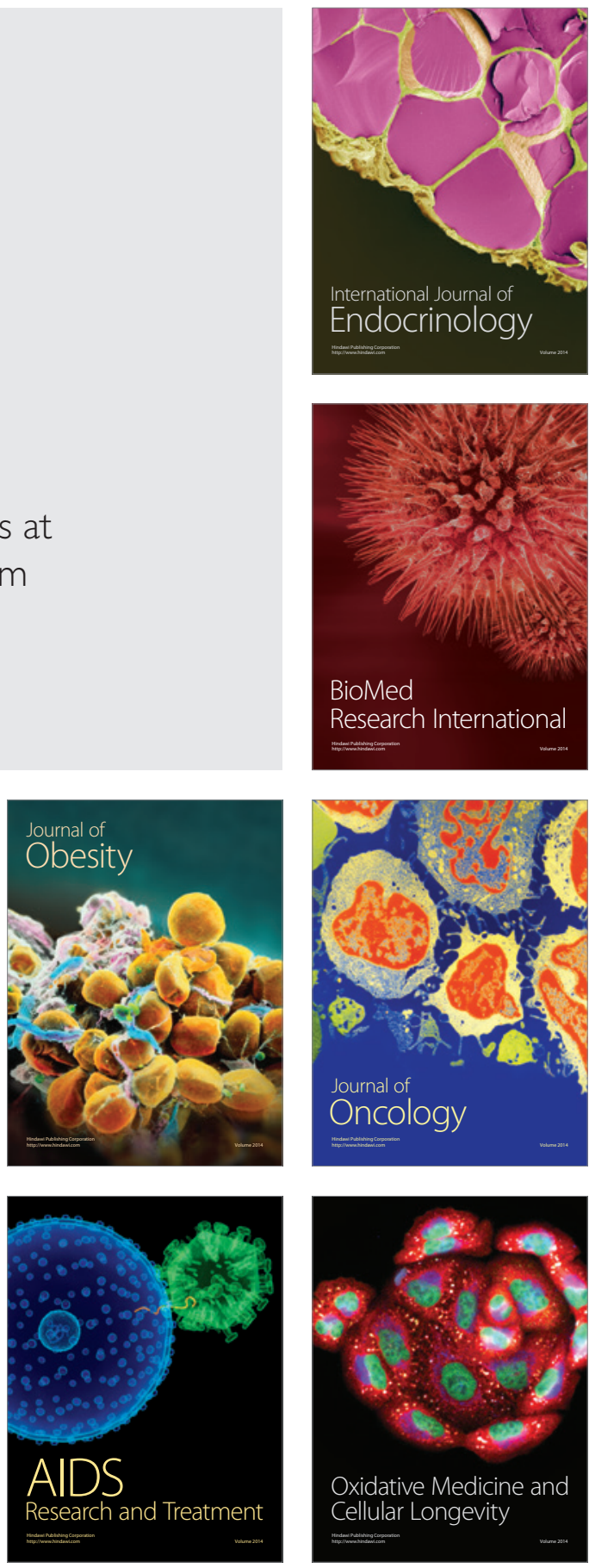